\title{
Enhancement of the Natural Ventilation within Commercial and Traditional Wind Towers in Arid Environments
}

\author{
N. Sakhri ${ }^{1}$, Y. Menni ${ }^{2}$ and H. Ameur ${ }^{3 \dagger}$ \\ ${ }^{1}$ Laboratory of Energy in Arid Areas (ENERGARID), University of Bechar, P.O. Box 417, 08000, Bechar, \\ Algeria \\ ${ }^{2}$ Unit of Research on Materials and Renewable Energies, Department of Physics, Faculty of Sciences, \\ Aboubekr Belkaid University, P.O. Box 119, 13000, Tlemcen, Algeria \\ ${ }^{3}$ Department of Technology, University Centre of Naama, P.O. Box 66, Naama 45000, Algeria \\ †Corresponding Author Email: ameur@cuniv-naama.dz
}

(Received September 2, 2020; accepted April 4, 2021)

\begin{abstract}
Wind tower (catcher) is an old technique used to provide natural ventilation and thermal comfort in arid regions like Iran, and the Middle East. An attempt is made to improve the performance of such techniques by investigating the effects of the windward wall of a traditional wind tower. Four aerodynamic shapes are studied: circular, triangular, $U$ and square shape. Two- and three-dimensional numerical simulations are carried out to examine the internal and external pressure caused by wind in the region of Bechar (South-West of Algeria). The obtained results showed an increase of airflow velocity at the tower outlet connected directly to the ventilated space by 28 and $16 \%$ for the circular and triangular models, respectively, and a decrease by $22 \%$ for the U-model. The separation flow zone decreased in both circular and triangular models, in comparison with $U$ and square models. These results can improve the efficiency of natural ventilation of traditional and commercial wind towers.
\end{abstract}

Keywords: Aerodynamic behavior; Thermal comfort; Natural ventilation; Wind tower; Arid region.

\section{NOMENCLATURE}

$\begin{array}{ll}k & \text { kinetic energy } \\ U_{\mathrm{i}} & \text { velocity magnitude in the x direction } \\ U_{\mathrm{j}} & \text { velocity magnitude in the x direction } \\ U_{\mathrm{k}} & \text { velocity magnitude in the x direction } \\ V_{\mathrm{x}} & \text { air velocity in the x direction } \\ V_{\mathrm{y}} & \text { air velocity in the y direction } \\ V_{\mathrm{z}} & \text { air velocity in the } \mathrm{z} \text { direction } \\ \rho & \text { air density }\end{array}$

\section{INTRODUCTION}

Thermal comfort is vital for right living conditions and productivity inside buildings. In Algeria, the residential sector represents the highest energy consumption by $42 \%$ of national energy consumption (APRUE). A big part of this energy is provided to ensure thermal comfort, especially in hot arid regions like the south of Algeria. The use of HVAC equipment represents the most massive enduser in residential and office buildings, by almost two-thirds of the total energy use (Calautit et al. 2015; Liping and Hien, 2007). Relevant analyses on

\author{
$\varepsilon \quad$ dissipation of kinetic energy \\ $\delta_{\mathrm{ij}} \quad$ generic functions \\ $\mu_{\mathrm{t}} \quad$ turbulent viscosity
}

the enhancement of natural ventilation inside traditional and commercial wind towers in arid regions were reported in the literature. For example, see (Arinami et al. 2019; Chen et al. 2019; Cheng et al. 2018; Dehghan et al. 2013; Han et al. 2018; Liu et al. 2018; Liu et al. 2019; McCartney and Lefsrud, 2018; Porras-Amores et al. 2019; Weerasuriya et al. 2019; Yuan et al. 2019). In these analyses, various situations under different models were reported.

The wind tower (catcher) is an old technique that is used to provide natural ventilation and thermal 
comfort in arid regions like Iran, and the Middle East. Many researchers around the globe have studied this technique and its evolution from 1,300 years to nowadays. The traditional and vernacular architectures have used these giant structures with heights until 33 meters and different channel shapes (square, circular, rectangular, etc.) to catch the wind with high velocity in altitudes. The structures were connected to the building by side walls, courtyard and roofs. They were called: "traditional windcatcher". The modern bioclimatic architecture considers the windcatcher as a renewable technique, and it is known as "commercial windcatcher". It is integrated to the buildings only by roofs, and their heights don't exceed $2 \mathrm{~m}$ with high performance due to many improvements.

\section{RELATED WORKS}

Several natural ventilation techniques have been used across the history of humankind (Sakhri et al. 2020). The wind tower, the so-called windcatcher (Montazeri and Azizian, 2008), is one of these techniques. It is used to drive the wind inside buildings in the humid, semi-arid and arid regions for 1300 years B.C. to provide thermal comfort without any consumption which ensures compatibility with modern requirements (Montazeri, 2011). (Moghaddam et al. 2011) studied the performance of traditional Iranian wind towers. They found that this technique is effective in living spaces cooling in arid areas. (Bahadori et al. 2016) reported in their work that the technique of wind towers back to the Pharaohs period and keep existing until nowadays. Due to its simple design, ease of installation and operation, the wind tower can be integrated as an element of bioclimatic architecture in harmony with our modern lifestyle (Suleiman and Himmo, 2012). (Ameer et al. 2016) studied the influence of typology and the shape of the building roof on natural ventilation efficiency using wind tower. They concluded that the type and shape of the roof directly influences the performance of the technique by varying the pressure gradients created across the envelope.

(Afshin et al. 2016) studied the effect of angle of attack of incident winds on the natural ventilation performance of the two-sided wind tower. The study concluded that the direction of the wind has a major influence on the performance of this technique and that the ideal angle is between $39^{\circ}$ and $55^{\circ}$.

The influence of the internal geometry of the tower on internal thermal comfort in arid regions such as the city of Yazd in Iran has been studied numerically by (Hosseini et al. 2016). By reducing the width of the tower from 2.5 to $2 \mathrm{~m}$, the induced air flow and the flow speed are increased by $34 \%$ and $50 \%$ respectively. A new rotary wind tower is studied numerically using a CFD code (FLUENT) by (O'Connor et al. 2015). (Dehghani-Sanij et al. 2015) proposed a new design of the wind tower which rotates and adapts with the conditions of variable winds which will be beneficial in regions with variable winds.
(Calautit et al. 2017) conducted a numerical and experimental study (CFD) on a multidirectional wind tower equipped with a vertical heat exchanger. A decrease of $12{ }^{\circ} \mathrm{C}$ in the air temperature is obtained which contributes to the improvement of the internal thermal comfort in summer. A new modular wind tower with wet surfaces has been studied by (Khani et al. 2017). They found that the new design was able to reduce the air temperature by $10{ }^{\circ} \mathrm{C}$ and increase the relative humidity by $36 \%$.

Improving natural ventilation performance of such renewable and ecological technique require the study of different parameters influence which affecting external and internal pressure field considerable as the key element influencing wind induced natural ventilation. A very important geometrical parameter was neglected and never been studied before, it is the wind tower or wind catcher windward facing the prevailing winds. When wind facing a structure, a positive pressure zone is created in the windward (structure front) and negative one is created in the leeward (structure back). The pressure difference between the windward and the leeward is the internal airflow driving force in the presence of opening like windows and doors.

To maximize this pressure difference, windward geometry of traditional wind catcher is studied numerically by CFD simulation. Four windward aerodynamic shapes are studied for the first time: circular, triangular, $\mathrm{U}$ and square shape. 2D and 3D numerical simulation are carried out to study the internal and external pressure caused by wind in the region of Béchar (South-West of Algeria). The Four models are studied separately (without the house or the ventilated space) for better comparison and to avoid any influence on simulation results.

\section{GEOMETRY UNDER SIMULATION}

The external domain (macroclimate) is composed of atmospheric air considerable incompressible ( $\rho=$ constant $)$. The dimensions of the domain are taken under the recommendations of (Revuz, 2011) (Fig. 1a), where $H$ is the wind tower height equal to $9 \mathrm{~m}$. The dimensions of the four studied models are presented in (Fig. 1b). The inlet and outlet sections of the tower are $1 \mathrm{~m}^{2}$ and $0.5 \mathrm{~m}^{2}$, respectively.

\section{Computational grid information}

The grid-mesh of the outside faces (windward, leeward and lateral faces) with a high resolution has a great importance on simulations results. Many grid cases were studied and compared. The choice of grid type leads to the choice of better meshing strategy with less influence on numerical results. High-resolution computational grids were created for the studied cases. A structured type was used for the external domain or called macro-climate and also for square wind tower model (in particularly inside wind tower). However, an unstructured one by using hexahedral cells was used for the circular, triangular and $\mathrm{U}$ models due to the complexity of their geometries. 


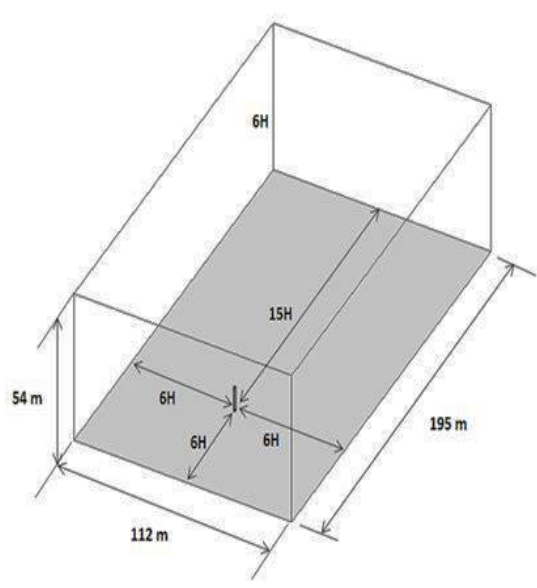

(a) Dimensions of the macro-climate

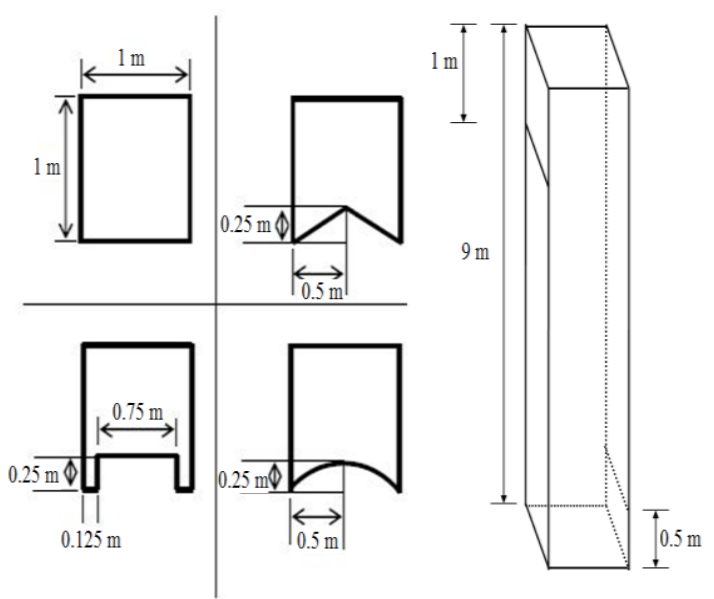

(b) Dimensions of the 4 studied models

Fig. 1. Geometry of the studied problem.

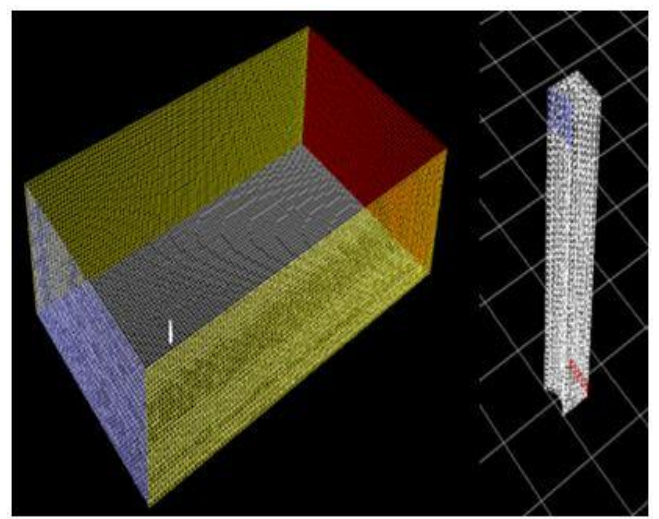

Fig. 2. View of the grid used in the simulation.

The main grid characteristics are as follow: 150,000 cells, 450,000 faces, and 159,000 nodes. These values were slightly higher in the $\mathrm{U}$ model because of the additional faces (Fig. 2).

\section{Mesh independence analysis}

Mesh independence study was conducted for the four studied models (square, circular, triangular, and U-shape). The study was performed by employing the k- $\varepsilon$ turbulence model or also called 'standard model' for simple objectives: keeping computational costs low. Different types and sizes of mesh were used to determine their effect on the simulation results quality. Instructed mesh (hexahedral) and structured meshes were used and the numerical results were compared. As a result, the mesh independency test showed that the overall simulation results stability by the $\mathrm{k}-\varepsilon$ turbulence model is more reasonable by using a structured mesh in comparison with the unstructured mesh by $31 \%$, for all considered models.

\section{Blocking ratio}

The blocking ratio is defined as the ratio between the vertical surface of the building and the inlet surface of the simulated domain (macro). It is recommended that this ratio does not exceed 3\%
[14]. For our study, the blocking ratios for the 2D and $3 \mathrm{D}$ cases are equal to 0.89 and $0.14 \%$, respectively. These values are selected as recommended in the literature.

\section{Boundary conditions}

For the external domain, the inlet velocity of wind $\left(V_{\mathrm{x}}=1\right.$ and $\left.2 \mathrm{~m} / \mathrm{s}, V_{\mathrm{y}}=V_{\mathrm{z}}=0\right)$. This value allows the prevailing winds. The attack angle of the wind is supposed to be $0^{\circ}$. Symmetry condition for both sides and top faces and pressure outlet for domain outlet. Velocity inlet boundary condition is used for the tower inlet and pressure outlet for the tower outlet. The wind tower faces and domain ground are considered as walls $(0 \mathrm{~m}$ for the roughness height $)$ (Fig. 3).

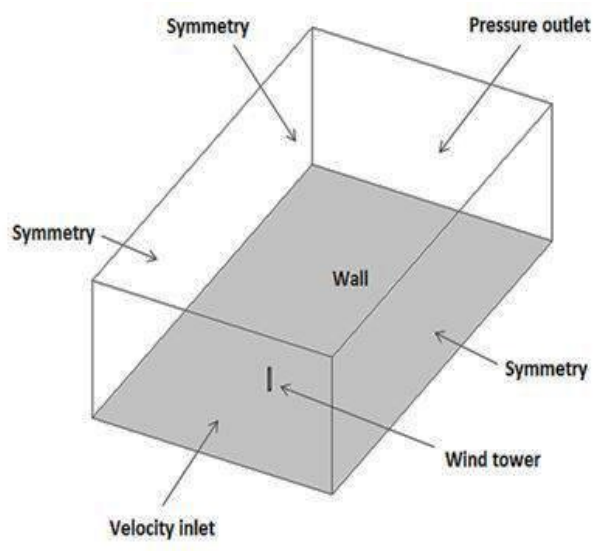

Fig. 3. Boundary conditions for the external domain.

The wind profile is a parabolic profile due to the presence of surface roughness and change from $v=0 \mathrm{~m} / \mathrm{s}$ near the surface to $v_{\max }$ at a given height. In our case, it is taken as $9 \mathrm{~m}$. In the present study, we suppose that the wind catcher is situated in an 
isolate site (with no obstacles and a smooth surface) and this hypothesis encouraged us to consider the wind profile as a stable one.

\section{Turbulence model}

The standard $k-\varepsilon$ turbulence model is used in the study. This model can predict well the separate and reattachment flow and gives satisfactory results in natural ventilation studies (Gao and Chow, 2005; Ghadiri et al. 2012). Most of the studies on the use of $k-\varepsilon$ model show its capability in indoor airflows simulation with low simulation costs. It is also found that this model gives a very satisfying simulation results in indoor air quality subjects (Teodosiu et al. 2014).

\section{GOVERNING EQUATIONS}

The continuity and momentum equations for threedimensional incompressible and steady flows are given as follows (Devi and Kumar, 2012):

$$
\begin{aligned}
& \frac{\partial \rho}{\partial t}=\frac{\partial}{\partial x_{i}}\left(\rho U_{i}\right)=0 \\
& \frac{\partial}{\partial x_{i}}\left(\rho U_{i} U_{j}\right)=-\frac{\partial p}{\partial x_{i}} \\
& +\frac{\partial}{\partial x_{j}}\left[\mu\left(\frac{\partial U_{i}}{\partial x_{j}}+\frac{\partial U_{j}}{\partial x_{i}}-\frac{2 \partial U_{k}}{3 \partial x_{k}} \delta_{i j}\right)\right]
\end{aligned}
$$

where $\rho$ is the fluid density. The term on the left side of hand in Eq. (2) presents the convection and the terms on the right side present the pressure gradient and the divergence of the stress tensor, respectively.

The turbulent regime is characterized by fluctuations in the mean velocity and other variables, and it is required to incorporate the effect of these parameters into the CFD model in order to obtain accurate predictions. This is performed by using a turbulence model. Using the sum of an equilibrium and a fluctuating component, Eq. (2) becomes as follows:

$$
\begin{aligned}
& \frac{\partial}{\partial x_{i}}\left(\rho U_{i} U_{j}\right)=-\frac{\partial p}{\partial x_{i}} \\
& +\frac{\partial}{\partial x_{j}}\left[\mu\left(\frac{\partial U_{i}}{\partial x_{j}}-\frac{2 \partial U_{k}}{3 \partial x_{k}} \delta_{i j}\right)\right] \\
& +\frac{\partial}{\partial x_{j}}\left(\rho \overline{U_{i} U_{j}}\right)
\end{aligned}
$$

The last term at the right side in Eq. (3) is called the Reynolds stresses. The standard $k-\varepsilon$ model was employed in this work to solve this term.

The solutions for $k$ and $\varepsilon$ are utilized to solve the turbulent viscosity $\left(\mu_{\mathrm{t}}\right)$. The following constants of the standard $k-\varepsilon$ model are used: $C_{\mu}=0.09, C_{1}=1.44$, $C_{2}=1.92, \rho_{\mathrm{k}}=1$ and $\rho_{\varepsilon}=1.314$, respectively [31]. In this numerical study, FLUENT 6.3 solver which is based on the finite volume method was used to solve the governing equations. The SIMPLE algorithm was used to perform the pressure-velocity coupling. The second order upwind scheme was also selected.

\section{RESULTS AND DISCUSSION}

Before beginning our investigation, the reliability of used computer software (Fluent 6.3) and the correctness of the employed numerical method have been checked. For this purpose, we referred to the experimental work realized by (Błazik-Borowa et al. 2011). For the same geometrical conditions as those used by these authors, the vertical profile of the average inlet velocity is presented in Fig. 4. As observed in this Figure, the comparison of our predicted results with the experimental data of Bazik-Borowa and his co-workers shows a satisfactory agreement.

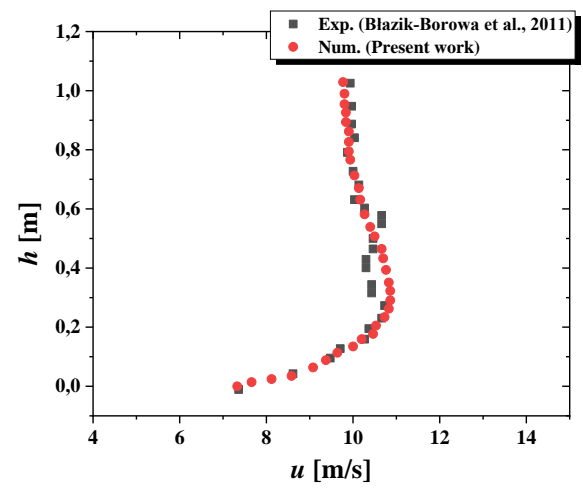

Fig. 4. The vertical profile of the average inlet velocity at $x / a=-4$ (validation)

We note the three models of windward face (triangle, half circle, and $U$ shape) are highlighted in this paper for the first time. The square wind catcher is a traditional wind catcher and the validation of numerical results was made against the experimental results that are available in the literature.

The obtained 2D results show that the four aerodynamic shapes of the windward wall facing the prevailing winds show a region of positive pressure in the windward and negative pressure in leeward with a recirculation flow in this zone and a detachment of wind flow in both sides of the wind tower models (Figs. 5 and 6). We note the dimensions of the outside domain were chosen under the recommendations of Revuz (2011). Reynolds number of the macro climate is $116 \times 10^{6}$ (fully turbulent), and at the wind tower inlet it is equal to $2 \times 10^{6}$.

The circular and triangular towers present the biggest region of negative pressure and critical areas situated in the corners due to detachment of flow when the pressure gets its lower values ( -7 to $6 \mathrm{~Pa}$ ) (Figs. 5a and 5b). This region of pressure drop is bigger in the circular model (Fig. 6a). The region where wind velocity becomes lower (close to 0 ) exist in the three models causing a bigger region of stagnation flow and bigger positive pressure region more than the square shape model (Fig. 7). 


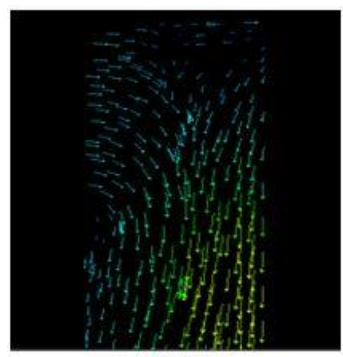

(a)

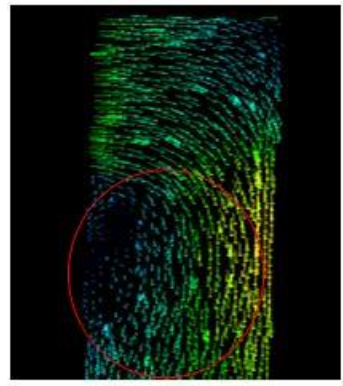

(c)

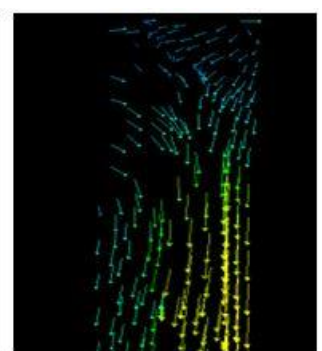

(b)

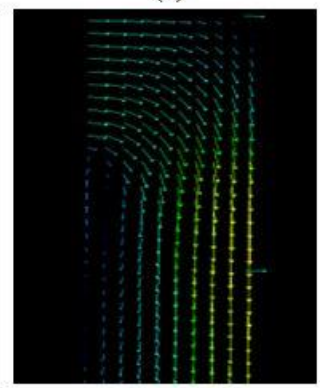

(d)
Fig. 5. Separation of flow in four wind tower models: (a) circular, (b) triangular, (c) U, (d) square $(y=56 \mathrm{~m})$.

Compared to the square model, the airflow velocity at the outlet increases by $28 \%$ and $16 \%$ in the circular and triangle models, respectively, while it decreases by $22 \%$ in U-model. To get these results, we have divided the outlet zone in nine equal subzones for all of the studied models. The square

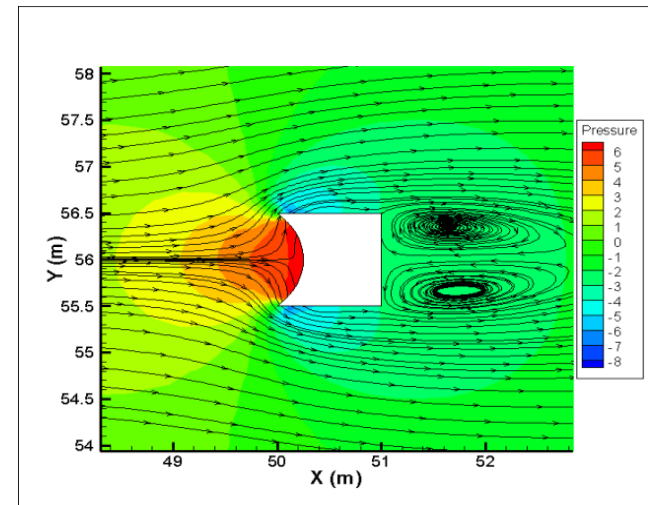

(a)

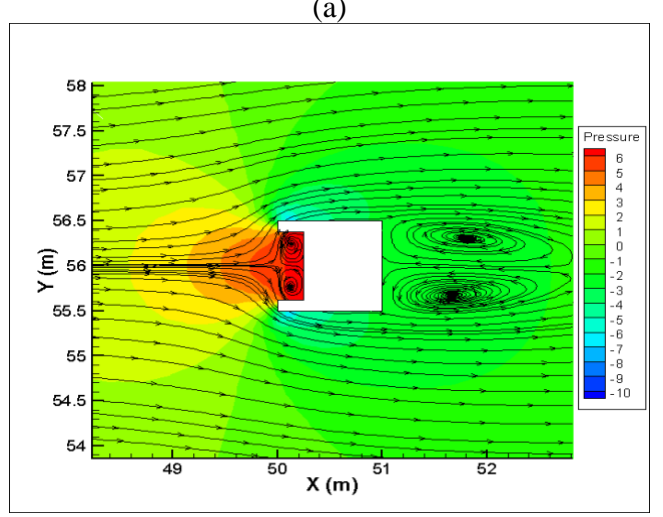

(c) model was taken as a reference and the results were compared to this model.

For 3D simulation results, reported in Fig. 8, the analysis of total pressure inside tower models shows the existence of higher-pressure zone in the corner facing tower inlet in all models called stagnation zone and begin to reduce but the values of internal pressures change from a model to another. For the square model, in Fig. 8(d), internal pressure is (30$35 \mathrm{~Pa}),(50-60 \mathrm{~Pa})$ in circular model (Fig. 8(a)), (40$50 \mathrm{~Pa}$ ) for triangular model (Fig. 8b), and (20-24 Pa) in the U model (Fig. 8c). The sharp corners of the three models (circular, triangular and $\mathrm{U}$, respectively in Fig. $8 \mathrm{a}, 8 \mathrm{~b}$, and $8 \mathrm{c}$ ) create recirculation zones inside wind tower, but the bigger effect exists in $U$ model which can reduce airspeed at the wind tower outlet. The result of airflow velocity, in Fig. 9, at the tower outlet (discharge opening) shows an over-prediction in the circular model for $1 \mathrm{~m} / \mathrm{s}$ wind speed (Fig. 9a). For $V=2$ and $3 \mathrm{~m} / \mathrm{s}$, the circular model presents the highest airspeed at the outlet followed by triangular model. This result is due to two factors: (i) the increase in the internal pressure for the two models; and (ii) the reduction of the hydraulic diameter which conducts to higher Reynolds number and higher speeds across wind tower to the outlet. It is essential also to mention the reduction of the separation and recirculation zone under the lower edge of the tower inlet in both circular and triangular models in comparison with the square and $\mathrm{U}$ model.

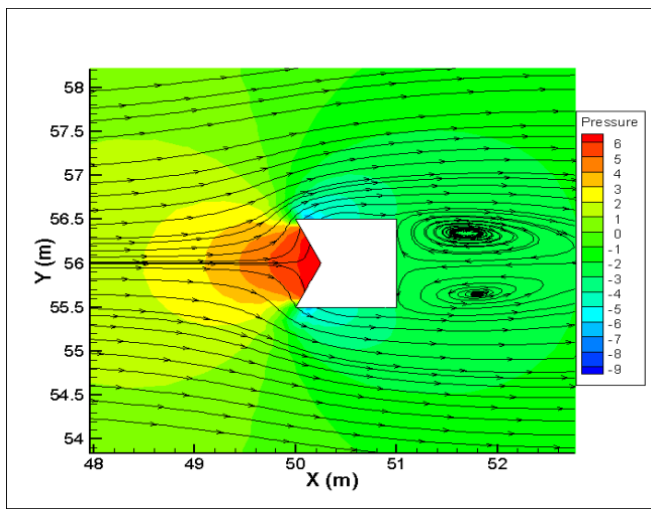

(b)

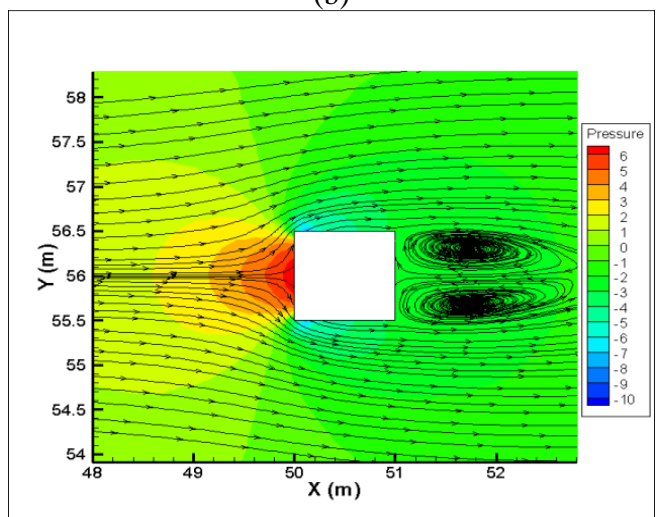

(d)

Fig. 6. 2D total pressure (Pa) in the four models: (a) circular, (b) triangular, (c) $U$ and (d) square. 


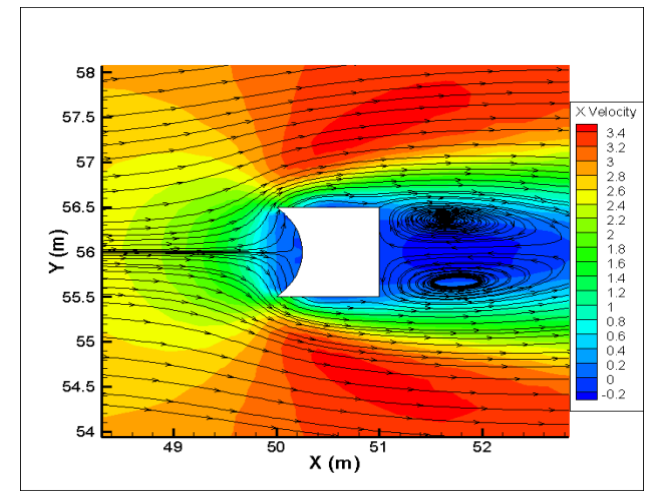

(a)

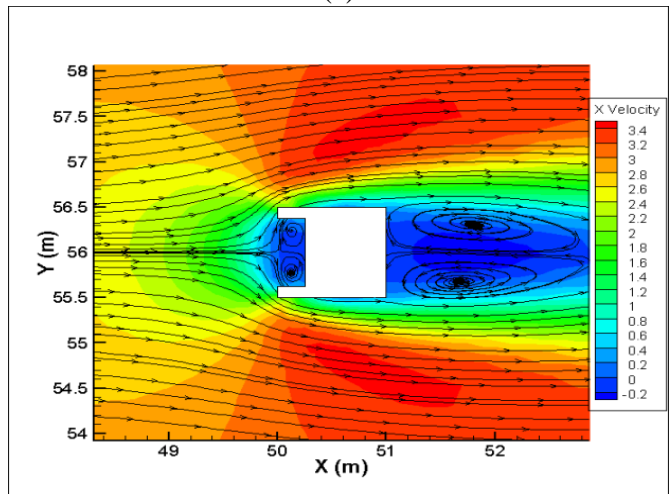

(c)

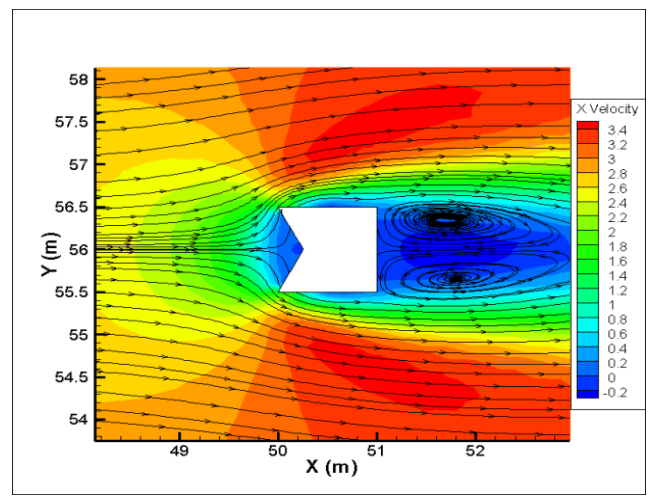

(b)

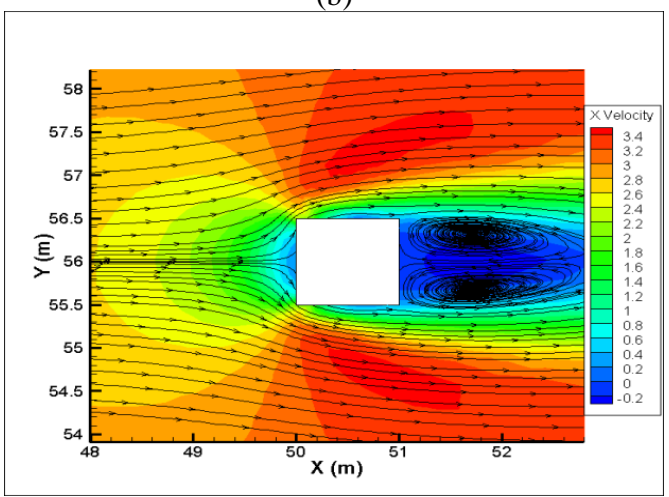

(d)

Fig. 7. 2D velocity magnitude (m/s) for the 4 models: (a) circular, (b) triangular, (c) $U$ and (d) square.

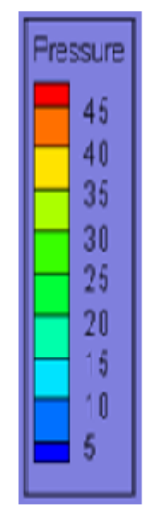

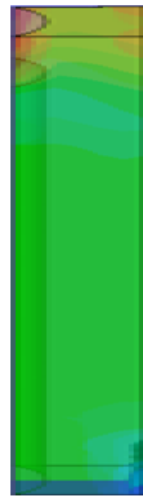

(a)

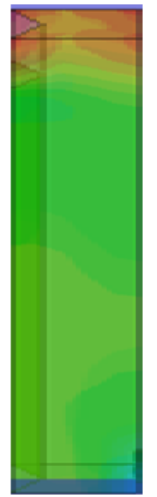

(b)

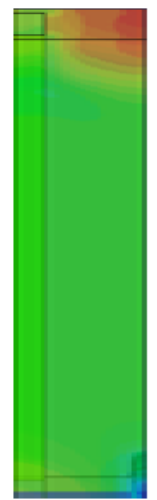

(c)

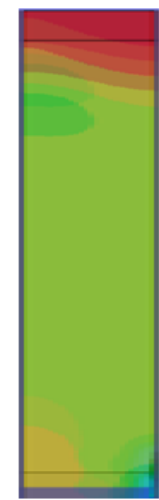

(d)

Fig. 8. 3D view of total pressure (Pa) for (a) circular, (b) triangular (c) $U$ shape and (d) square.

Table 1 Airflow velocity at the wind tower outlet $(z=0.25 \mathrm{~m})$.

\begin{tabular}{|c|c|c|c|c|}
\hline \multirow{2}{*}{$\begin{array}{c}\text { Wind speed } \\
(\mathrm{m} / \mathrm{s})\end{array}$} & \multicolumn{4}{|c|}{ Air velocity at tower outlet $(\mathrm{z}=0.25 \mathrm{~m})$} \\
\cline { 2 - 5 } & Rectangular & Triangular & Circular & $\mathrm{U}$ \\
\hline 1 & 2.43 & 2.96 & 6.27 & 1.93 \\
\hline 2 & 5.12 & 5.95 & 6.56 & 3.86 \\
\hline
\end{tabular}

The separation of flow can reduce significantly the airflow induced to the building (Dehghan et al. 2013). By changing the shape of the windward wall of traditional windcatcher, this problem can be resolved, and the airflow rate induced in ventilated space must be increased (Table 1).

\section{CONCLUSION}

Natural ventilation by wind towers is an effective technic used in the past and the present to provide thermal comfort, especially in hot arid regions. 


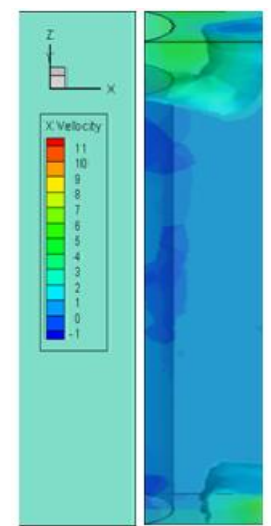

(a)

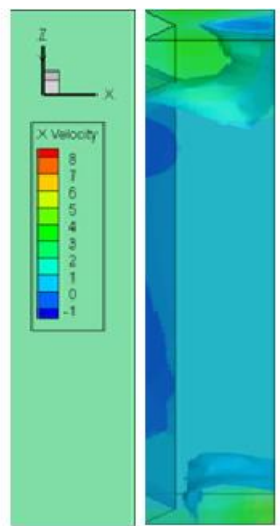

(b)

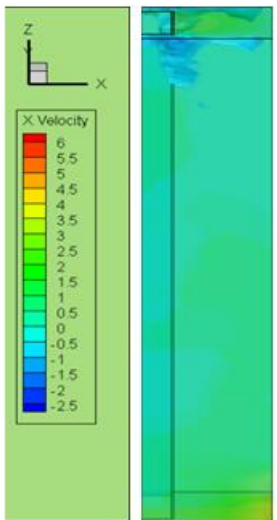

(c)

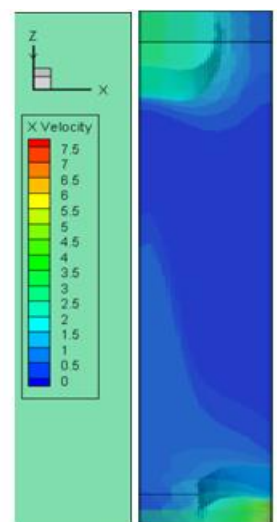

(d)

Fig. 9. 3D view of velocity magnitude (m/s) for (a) circular, (b) triangular (c) $U$ shape and (d) square.

The aerodynamic shape of the windward wall of a traditional wind tower is questioned in this paper. Traditional wind tower often used the rectangular and square shape. Three new models are proposed: circular, triangular and the $\mathrm{U}$ shape studied in a project context for the first time.

The obtained results confirm the importance of the geometry of the wind tower windward wall to improve the performance of this technic. In comparison with the square model, both circular and triangular models present external and internal pressures much higher, on the contrary of the $U$ model. The higher-pressure difference between the inside and the outside of the wind tower conducted to further enhancement in the natural ventilation.

Airflow speed at the tower outlet connected directly to the ventilated space increase considerably in comparison with the square model by $(28 \%)$ for the circular model, (16\%) for triangular model and decrease for the U-model by $(-22 \%)$. This increase in airflow velocity leads to a significant airflow rate induced to the ventilated space and it reduces the internal temperature inside the building. Stagnation and separation of flow at the wind tower inlet zone are two major problems in this technic. By changing the shape of the windward wall of the traditional wind tower, i.e. using circular and triangular shapes, the region of separation flow was significantly reduced, and the natural ventilation capacity of windcatcher increased. The obtained results can improve the performance of both traditional and commercial (modern) windcatcher.

The concept of changing the wind tower windward from regular forms to new one is studied for the first time and due to the absence of experimental data in this case, our future works will be based on validation of those results by experimental investigation in wind tunnel.

\section{REFERENCES}

Afshin, M., A. Sohankar, M. D. Manshadi and M. K. Esfeh (2016) An experimental study on the evaluation of natural ventilation performance of a two-sided wind-catcher for various wind angles. Renewable Energy 85, 1068-1078.

Ameer, S. A., H. N. Chaudhry and A. Agha (2016) Influence of roof topology on the air distribution and ventilation effectiveness of wind towers. Energy and Buildings 130, 733746.

Arinami, Y., S. I. Akabayashi, Y. Tominaga and J. Sakaguchi (2019) Performance evaluation of single-sided natural ventilation for generic building using large-eddy simulations: Effect of guide vanes and adjacent obstacles. Building and Environment 154, 68-80.

Bahadori, M. N., A. Anij and A. Sayigh (2016) Wind Towers. Springer.

Błazik-Borowa, E., J. Bęc, T. Nowicki, T. Lipecki, J. Szulej and P. Matys (2011) Measurements of flow parameters for 2-D flow around rectangular prisms of square and rectangle cross-sections located on the ground. Archives of Civil and Mechanical Engineering 11, 533551.

Calautit, J. K., B. R. Hughes, D. O'Connor, S. S. Shahzad (2017) Numerical and experimental analysis of a multi-directional wind tower integrated with vertically-arranged heat transfer devices (VHTD). Applied Energy $185,1120-1135$.

Calautit, J. K., B. R. Hughes and S. S. Shahzad (2015) CFD and wind tunnel study of the performance of a uni-directional wind catcher with heat transfer devices. Renewable Energy 83, 85-99.

Chen, J., G. S. Brager, G. Augenbroe and X. Song (2019) Impact of outdoor air quality on the natural ventilation usage of commercial buildings in the US. Applied Energy 235, 673684.

Cheng, J., D. Qi, A. Katal, L. L. Wang and T. Stathopoulos (2018) Evaluating wind-driven natural ventilation potential for early building 
design. Journal of Wind Engineering and Industrial Aerodynamics 182, 160-169.

Dehghan, A., M. K. Esfeh and M. D. Manshadi (2013) Natural ventilation characteristics of one-sided wind catchers: experimental and analytical evaluation. Energy and Buildings $61,366-377$

Dehghani-Sanij, A. R., M. Soltani and K. Raahemifar (2015) A new design of wind tower for passive ventilation in buildings to reduce energy consumption in windy regions. Renewable and Sustainable Energy Reviews $42,182-195$

Devi, T. T. and B. Kumar (2012) CFD simulation of flow patterns in unbaffled stirred tank with CD-6 impeller. Chemical Industry and Chemical Engineering Quarterly 18, 535-546.

Gao, Y. and W. Chow (2005) Numerical studies on air flow around a cube. Journal of Wind Engineering and Industrial Aerodynamics 93, 115-135

Ghadiri, M. H., M. F. Mohamed and N. L. N. Ibrahim (2012) Cfd analysis of natural ventilation behaviour in four sided wind catcher, Proceedings of World Academy of Science, Engineering and Technology, World Academy of Science, Engineering and Technology (WASET). pp. 704.

Han, D. H., S. Kim, J. H. Choi, Y. S. Kim, H. Chung and $\mathrm{H}$. Jeong N. Watjanatepin, C. Ruangpattanawiwat, and S.-H. Choi (2018) Experimental study on thermal buoyancyinduced natural ventilation. Energy and Buildings 177, 1-11.

Hosseini, S., E. Shokry, A. A. Hosseini, G. Ahmadi and J. Calautit (2016) Evaluation of airflow and thermal comfort in buildings ventilated with wind catchers: Simulation of conditions in Yazd City, Iran. Energy for Sustainable Development 35, 7-24.

Khani, S., M. Bahadori and A. Dehghani-Sanij (2017) Experimental investigation of a modular wind tower in hot and dry regions. Energy for Sustainable Development 39, 2128.

Liping, W. and W. N. Hien (2007) Applying natural ventilation for thermal comfort in residential buildings in Singapore. Architectural Science Review 50, 224-233.

Liu, C., J. Yang, S. Ji, Y. Lu, P. Wu and C. Chen (2018) Influence of natural ventilation rate on indoor PM2. 5 deposition. Building and Environment 144, 357-364.

Liu, Y., Y. Xiao, J. Chen, G. Augenbroe and T. Zhou (2019) A network model for natural ventilation simulation in deep buried underground structures. Building and Environment 153, 288-301.
McCartney, L. and M. G. Lefsrud (2018) Field trials of the natural ventilation augmented cooling (NVAC) greenhouse. Biosystems Engineering 174, 159-172.

Moghaddam, E. H., S. Amindeldar and A. Besharatizadeh (2011) New approach to natural ventilation in public buildings inspired by Iranian's traditional windcatcher. Procedia Engineering 21, 42-52.

Montazeri, H. (2011) Experimental and numerical study on natural ventilation performance of various multi-opening wind catchers. Building and Environment 46, 370-378.

Montazeri, H. and R. Azizian (2008) Experimental study on natural ventilation performance of one-sided wind catcher. Building and Environment 43, 2193-2202.

O'Connor, D., J. Calautit and B. R. Hughes (2015) Effect of rotation speed of a rotary thermal wheel on ventilation supply rates of wind tower system. Energy Procedia 75, 17051710

Porras-Amores, C., F. R. Mazarrón, I. Cañas and P V. Sáez (2019) Natural ventilation analysis in an underground construction: CFD simulation and experimental validation. Tunnelling and Underground Space Technology 90, 162-173.

Revuz, J. (2011) Numerical simulation of the wind flow around a tall building and its dynamic response to wind excitation, University of Nottingham.

Sakhri, N., Y. Menni, H. Ameur, A. J. Chamkha, N. Kaid, M. Bensafi, G. Lorenzini, O. D. Makinde (2020). Investigation of the natural ventilation of wind catchers with different geometries in arid region houses. Journal of Mechanical Engineering and Sciences 14(3), $7109-7124$

Suleiman, S. and B. Himmo (2012) Direct comfort ventilation. Wisdom of the past and technology of the future (wind-catcher). Sustainable Cities and Society 5, 8-15.

Teodosiu, C., V. Ilie and R. Teodosiu (2014) Appropriate CFD turbulence model for improving indoor air quality of ventilated spaces. Mathematical Modelling in Civil Engineering 10, 28-42.

Weerasuriya, A. U., X. Zhang, V. J. Gan and Y. Tan (2019) A holistic framework to utilize natural ventilation to optimize energy performance of residential high-rise buildings. Building and Environment 153, 218-232.

Yuan, C., R. Shan, A. S. Adelia, A. Tablada, S. K. Lau and S. S. Y. Lau (2019) Effects of vertical farming on natural ventilation of residential buildings. Energy and Buildings $185,316-325$. 